\title{
Usos do tempo nas Comunidades Autónomas. Unha aproximación á conciliación laboral e familiar a través dos índices de igualdade
}

Yolanda López Álvarez

Ana Salomé García Muñiz ${ }^{1}$

Facultade de Economía e Empresa, Universidade de Oviedo, España

\section{RESUMO}

A conciliación da vida laboral, familiar e persoal é un dos retos máis importantes nas sociedades desenvolvidas actuais. Neste traballo, desenvólvese unha análise estatística sobre a conciliación da vida nas diferentes comunidades autónomas, para determinar as posibles diferenzas existentes. Para iso, tómase como referencia a Enquisa de Emprego do tempo 2009-2010, realizada polo INE. A aplicación de indicadores de igualdade entre homes e mulleres a estes datos permite desvelar as diferenzas en canto á igualdade social, calidade de vida, autonomía persoal, traballo doméstico e produtividade. Os resultados suxiren a persistencia da asignación tradicional de roles de xénero en canto á autonomía, calidade de vida e igualdade social, principalmente. A partir destes índices, a análise factorial revela patróns diferenciados entre territorios, obtendo cinco grupos diferenciados de comunidades autónomas.

Palabras chave: conciliación, xénero, usos do tempo, índices de igualdade.

\section{Introdución}

A necesidade de atopar o equilibro entre todas as facetas da nosa vida lévanos a falar de conciliación. A conciliación da vida profesional, privada e familiar está relacionada cun tema moi importante na actualidade, a igualdade entre homes e mulleres. Non só é un tema das mulleres. Cada vez máis persoas teñen a necesidade de conciliar a vida profesional e familiar, sobre todo se teñen fillos ou persoas dependentes ao seu cargo (Papí, 2005). Esta necesidade xorde como consecuencia de cambios sociais e culturais, sobre todo trala incorporación xeneralizada da muller ao mundo laboral. Actualmente, tanto o home como a muller traballan fóra de casa pero, malia os cambios sociais experimentados nos últimos anos, despois da xornada laboral son as mulleres as que adoitan adicar máis tempo ás tarefas do fogar. Algúns indicadores laborais que ratifican esta afirmación son a taxa de emprego das mulleres con fillas ou fillos pequenos ao seu cargo, o uso do emprego a tempo parcial entre as mulleres (Giménez-Nadal et a 0., 2012). Segundo os datos dispoñibles por Eurostat en 2010, España é un dos países cunha maior diferenza entre as taxas de actividade de homes $(69,1 \%)$ e mulleres $(55,8 \%)$, o número de mulleres con fillos e/ ou fillas menores que traballan fóra de casa é, sistematicamente menor ao dos homes e o 23,2\% das mulleres elixen, en moitos casos non voluntariamente (Scott, 1993; Borderías et a 0., 1994; Arbaiza, 2000 , entre outros), un emprego a tempo parcial, cifra que se reduce ao 5,4\% no caso dos homes.

A crise financeira actual acentuou a desigualdade en todos os ámbitos (Pearson e Sweetman, 2011). Ao analizar a desigualdade en función do xénero dos traballadores, obsérvase que, durante a crise, o desemprego estivo moi presente nos países desenvolvidos e non afectou do mesmo xeito aos homes cas mulleres. Ata o momento, os máis afectados foron os homes polos sectores nos que traballan, por exemplo, a construción. Con todo, prevese que o desemprego feminino aumente xa que os sectores nos que abundan mulleres son os 
que están sufrindo máis recortes, por exemplo a educación ou a sanidade (Pearson e Sweetman, 2011) 1 .

A consecución da conciliación cumpre un papel fundamental na política de igualdade de oportunidades entre homes e mulleres, tanto na Unión Europea como nos distintos Estados membros, entre eles España. O logro dun equilibrio entre a vida familiar e a laboral repercute na calidade de vida dos traballadores, aínda que tamén afecta ás empresas. A dificultade de conciliar a vida laboral e familiar supón problemas de saúde e estrés que repercuten non só a nivel persoal senón tamén a nivel empresarial (Tobío, 2005; OECD, 2007). Dende a perspectiva das empresas, a conciliación entre a vida laboral e familiar considérase un problema importante (Meil et a o., 2010), nembargantes, diversos estudos sinalaron as posibles vantaxes de instituír medidas activas que a favorezan, tales como, unha diminución dos problemas de saúde, un aumento da motivación dos traballadores, unha redución do absentismo e dos atrasos no traballo, e, como consecuencia de todo iso, un efecto positivo sobre a produtividade (De Luis et a o., 2002).

A máis longo prazo, polo tanto, a economía no seu conxunto beneficiaríase. Segundo a Comisión Europea, "as políticas de conciliación son a resposta chave aos retos económicos e demográficos a longo prazo, e débense esixir como medio para estimular o crecemento" (Eurofound, 2010, pp. 6).

En suma, a conciliación como proxecto político diríxese non só á igualdade de oportunidades entre homes e mulleres, senón tamén a un aumento da produtividade nas empresas e unha mellora na calidade de vida e de traballo dos individuos. A conciliación laboral e a calidade de emprego atópase entre un dos obxectivos da Axenda de Política Europea, expresamente recolleitos na Estratexia de Lisboa de 2000. Actualmente, a Estratexia Europa 2020 pretende crear máis emprego e acadar unha vida mellor fixando tres prioridades básicas: crecemento intelixente, crecemento sostible e crecemento integrador para conseguir unha economía social de mercado de Europa para o século XXI. A Comisión propón sete iniciativas para dirixir os avances. A iniciativa "Unha axenda para novas cualificacións e empregos", pretende crear condicións para modernizar os mercados laborais coa finalidade de aumentar os niveis de emprego e garantir a continuidade dos actuais modelos sociais. Para iso, os Estados membros deben promover novas formas de equilibrio entre a vida laboral e familiar, políticas de avellentamento activo e acrecentar a igualdade entre sexos para, entre outras cousas, avanzar na conciliación entre vida laboral e familiar e facilitar as transicións do mercado laboral (Comisión Europea, 2010).

O obxectivo deste traballo, é cuantificar dende o punto de vista estatístico, as diferenzas que existen entre as comunidades autónomas no relativo aos usos do tempo por xénero. Concretamente, proponse unha análise detallada, a través dos índices estatísticos de igualdade e técnicas multivariantes, dos usos do tempo polas persoas residentes nas devanditas comunidades que nos ofreza unha aproximación á similitude ou diferenza de patróns de conciliación familiar, laboral e persoal. Esta análise permitirá revelar as rexións nas que se deben promover iniciativas con preferencia e cales son os seus problemas básicos en canto á conciliación.

Malia que, nas sociedades avanzadas de hoxe persisten os valores tradicionais e patriarcais que implican que as mulleres asumen unha maior proporción do traballo no fogar (Balbo, 1978; Legarreta, 2008, entre outros), existen evidencias empíricas que resaltan as diferenzas entre territorios segundo o alcance das políticas activas de xénero e as

1 Pola contra, nos países en vías de desenvolvemento como América Latina e Asia, que se adican principalmente ás exportacións das industrias manufactureiras, o desemprego afectou máis ás mulleres. 
características do mercado laboral local (Gershuny, 2000), entre outros factores. Naqueles países onde as mulleres alcanzaron unha maior emancipación económica e/ ou unha mellor posición social grazas ás políticas activas de xénero, as relacións de xénero tenderon a ser máis igualitarias (Hook, 2010). Numerosos estudos (López e Lozares, 2007; Kovács e Casasa, 2007, entre outros) tamén sinalaron que as pautas de emprego están directamente vinculadas ás políticas familiares e, polo tanto, á dificultade que teñen as familias para compatibilizar o traballo e a familia.

En España, as comunidades autónomas presentan características diferenciais nos seus respectivos mercados laborais locais e un grao de acceso aos servizos de coidado que permitan atender as responsabilidades familiares (en especial, o coidado dos menores de seis anos e das persoas dependentes) non uniforme territorialmente. Dado que, actualmente, en España, os servizos sociais son competencia das rexións e os municipios, a oferta destes servizos sociais é moi desigual por rexións. O gasto público nos servizos familiares, as subvencións e deducións de impostos ás familias con fillos/as, a cobertura dos servizos públicos de educación infantil de 0 a 3 anos e a cobertura de asistencia domiciliaria á terceira idade nas diferentes comunidades autónomas implican un nivel de "desfamiliarización" (Esping-Andersen, 2000) moi diverso. É por iso que convén analizar as desigualdades de xénero fronte á conciliación do traballo e a vida persoal a nivel rexional.

A estrutura deste traballo é a seguinte. Tras unha breve recensión do marco conceptual da conciliación, detállase a información estatística empregada neste traballo, centrada na última Enquisa do Uso do Tempo do ano 2009-2010 elaborada polo INE. No apartado de metodoloxía, proponse un enfoque baseado nos diferentes índices estatísticos de igualdade que permitan abordar a conciliación laboral e familiar dende unha perspectiva multidimensional (Álvaro, 1994). O emprego destes índices a nivel de comunidades autónomas, permite ofrecer unha nova óptica na análise dos usos do tempo a nivel local, que desvela diferenzas non observables a través dunha análise descritiva. O emprego de técnicas multivariantes sobre os índices de igualdade completa e sintetiza a información dispoñible. Os resultados permiten ofrecer interesantes conclusións en canto á igualdade social, calidade de vida, autonomía persoal, traballo doméstico e produtividade por xénero e, grupos de comunidades autónomas con diferentes patróns no que se refire á conciliación.

\section{Conciliación: marco conceptual}

Entre a vida laboral, familiar e persoal existe unha relación de oposición, doutrinas contrarias ou odio, que responde basicamente a tres modelos: modelo de segmentación, modelo do desbordamento e modelo de conflito.

O primeiro modelo, "presupón que o mundo do traballo e o da vida familiar son esferas distintas e sen influencia ningunha entre elas. O modelo do desbordamento suscita que un destes dous mundos pode influír no outro. Este modelo propón dúas versións: modelo de compensación, que suscita que algunhas demandas ou satisfaccións das que poida carecer algunha das dúas esferas pode afectar e ata ser compensada pola outra, e o modelo instrumental, que suscita a posible instrumentalización dunha das esferas para conseguir maior éxito, benestar ou seguridade na outra. No modelo de conflito, as esferas do traballo, da vida familiar e persoal compiten polos recursos vitais da persoa, entre os que se atopa 0 tempo, proxectando unhas sobre as outras tanto os éxitos como as frustracións que se xeran" (Zedeck e Mosier, 1990, pp. 240-251).

O concepto de conciliación xorde claramente encadrado na última destas perspectivas, como se indica no Anexo.

\section{Información estatística: usos do tempo}


O tempo considérase un recurso do que todas as persoas dispoñen, sen ter en conta a súa clase social, a súa idade ou o seu sexo. Pode ser utilizado de xeito individual ou en grupo, en función dos intereses de cada persoa. Permite cuantificar a dedicación por parte dos diferentes individuos da sociedade, a realización de actividades como, por exemplo, traballo asalariado, traballo doméstico ou lecer, entre outros. Os usos do tempo poden xerar desigualdades de xénero. Por iso, é necesario detectar as posibles desigualdades que se poden xerar como consecuencia dunha mala utilización do tempo e intentar que o reparto de devandito tempo sexa máis equitativo e igualitario. As enquisas de emprego do tempo, constitúen unha ferramenta capaz de detectar as desigualdades na distribución do tempo dos homes e das mulleres.

Estas enquisas están orientadas tanto cara á faceta social como cara á económica. A parte social analiza os comportamentos das persoas para así detectar posibles desigualdades, é dicir, son unha ferramenta de traballo moi útil para detectar a orixe e o grao de desigualdade que existe nas actividades que se realizan día a día, para pescudar onde é necesaria unha maior intervención. A parte económica, permite saber o volume de traballo non retribuído que realizan as mulleres no ámbito doméstico e calcular canto contribúe o devandito traballo á riqueza nacional (Joyce e Stewart, 1999; Meil e Rogero, 2012)22.

A orixe das enquisas sobre o Uso do Tempo localízase a principios século XX cando comenzou a xurdir o interese por coñecer o tempo adicado ás diferentes actividades que realizan os individuos. O denominado estudo Szalai - por ser este o seu director-, desenvolvido a mediados dos anos 70, considérase o antecedente metodolóxico das actuais enquisas do uso do tempo (García Sanz, 2005).

En España, dende os anos noventa, realizáronse distintas enquisas e investigacións sobre os usos do tempo dende institucións públicas e/ ou privadas como o Consello Superior de Investigacións Científicas (CSIC), o Centro de Investigacións sobre a Realidade Social (CIRES), o Instituto Vasco de Estatística (EUSTAT), o Instituto da Muller ou o Instituto de Estatística de Cataluña (IDESCAT). Pola súa banda, o Instituto Nacional de Estatística (INE) publicou dúas Enquisas de Emprego do Tempo (EET): unha dos anos 2002-2003 e, outra dos anos 2009-2010.

Nas últimas décadas, a nivel internacional, estendéronse os estudos sobre o uso do tempo para a adopción de decisións políticas e de xestión empresarial por xénero (Gershuny, 1987; Pedrero, 2004; Fagan, 2007, entre outros). Nos anos 70, creouse a International Association for Estafe Use Research e, dende os anos 90, Eurostat fomentou a harmonización internacional das bases de datos sobre o emprego do tempo. En España, xurdiron traballos orientados á análise do uso do tempo principalmente dende o campo da socioloxía e da economía (Durán, 1991; Ramos, 1999; García Sainz, 1999 e 2007; Carrasco, 2005; Torns et a o., 2008; Legarreta, 2008; Durán e Roguero, 2009; González e Xurado-Guerreiro, 2009; Marcenaro e West, 2009; Rodríguez e Pis, 2010, entre outros).

Neste traballo, empregarase a información dispoñible na última Enquisa de Emprego do Tempo (EET) do 2009-2010. Segundo o documento metodolóxico sobre a devandita enquisa, publicado polo INE no 2011, a poboación obxecto desta enquisa é a do conxunto de fogares privados que residen en vivendas familiares en todo o territorio español e o conxunto de persoas de 10 ou máis anos de idade, membros do fogar, dos devanditos fogares. No deseño da mostra, utilizouse unha mostraxe bietápica con estratificación das unidades da primeira etapa (seccións censais). Os datos definitivos da EET corresponden a

2 Os datos sobre os usos do tempo son un instrumento chave para xerar Contas Satélite nas que se incorporan actividades produtivas non retribuídas de non-mercado. Véxase Durán (2012) para unha revisión detallada. 
11.538 vivendas e 19.295 persoas de 10 ou máis anos. A EET ofrece información desagregada a nivel das comunidades autónomas. A distribución da mostra de seccións entre comunidades autónomas realizouse considerando unha afixación de compromiso entre uniforme e proporcional asignando a cada comunidade un mínimo de 300 vivendas familiares. A distribución da mostra por comunidades autónoma recóllese no anexo.

As persoas elixidas na enquisa cumprimentaron un diario de actividades nun día concreto da semana previamente especificada entre o último trimestre do 2009 e dos tres primeiros do 2010. Defínese actividade como a acción realizada polo informante nun momento dado. A lista de actividades incluídas na EET do 2009-2010, recollida na táboa no 1 , constitúe unha adaptación ao marco español da lista de actividades harmonizada proposta por Eurostat nas súas directrices do 2008. Ditas actividades poden ser clasificadas, polo informante, como principais -as que realiza a persoa informante principalmente no período en cuestión- ou secundarias -as que realiza de forma simultánea no período de tempo considerado.

Táboa no 1. Lista de actividades incluídas na EET 2009-2010

\begin{tabular}{|l|l|}
\hline Coidados persoais & Durmir. comidas e bebidas, outros coidados persoais \\
\hline Traballo retribuído & $\begin{array}{l}\text { Traballo principal e secundario, actividades relacionadas co } \\
\text { traballo (incluída a procura de emprego) }\end{array}$ \\
\hline Estudos & $\begin{array}{l}\text { Estudos sen especificar, colexio, instituto ou universidade, } \\
\text { estudos durante o tempo libre }\end{array}$ \\
\hline Fogar e familia & $\begin{array}{l}\text { Actividades para o fogar e a familia non especificadas, } \\
\text { actividades culinarias, mantemento do fogar, confección e } \\
\text { coidado da roupa, xardinaría e coidado de animais, construción e } \\
\text { reparacións, compras e servizos, xestións do fogar, coidado de } \\
\text { nenos, axudas á adultos membros do fogar }\end{array}$ \\
\hline $\begin{array}{l}\text { Traballo voluntario e } \\
\text { reunións }\end{array}$ & $\begin{array}{l}\text { Traballo voluntario ao servizo dunha organización, axudas } \\
\text { informais a outros fogares, actividades participativas }\end{array}$ \\
\hline Vida social e diversión & Vida social, diversión e cultura, lecer pasivo \\
\hline $\begin{array}{l}\text { Deportes e actividades ao ar } \\
\text { libre }\end{array}$ & $\begin{array}{l}\text { Exercicio físico, exercicio produtivo, actividades relacionadas } \\
\text { cos deportes }\end{array}$ \\
\hline Afeccións e informática & Artes e afeccións, informática, xogos \\
\hline Medios de comunicación & $\begin{array}{l}\text { Lectura, ver a televisión, dvd ou vídeos, escoitar a radio ou } \\
\text { gravacións }\end{array}$ \\
\hline $\begin{array}{l}\text { Percorridos e emprego do } \\
\text { tempo non especificado }\end{array}$ & \\
\hline
\end{tabular}

Fonte: INE (2011).

\section{Metodoloxía: Indicadores de Igualdade}

A análise das desigualdades por xénero no uso do tempo pode ser realizado a partir de de diferentes propostas (Durán e Rogero, 2009; Moreno e Borràs, 2013, entre outros) centradas principalmente nas relacións do traballo retribuído e/ ou non retribuído con diversas características socio-económicas tales como a idade, o nivel de estudos, o tipo de xornada laboral ou o número de fillos, entre outros. 
Neste traballo, as diferenzas por xénero en canto aos usos do tempo nas diferentes comunidades autónomas analízanse a través de cinco indicadores de igualdade propostos por Álvaro (1994): Índice de Igualdade Social, Índice de Discriminación Respecto á Calidade de Vida, Índice Diferencial de Autonomía, Índice de Discriminación Respecto ao Traballo Doméstico e Índice Diferencial Respecto ao Traballo Produtivo. Estas medidas permiten unha aproximación cuantitativa conxunta aos obxectivos marcados na Estratexia Europa 2020 tales como a igualdade de sexos, mellora da calidade de vida ou da autonomía entre individuos. O Anexo inclúe información sobre a elaboración destes índices.

\section{Caso de estudo. Conciliación familiar e laboral nas comunidades autónomas}

Diversos estudos remarcaron as desigualdades existentes entre os homes e as mulleres á hora de realizar as actividades diarias. Ditas desigualdades son máis significativas cando falamos da carga global do traballo ${ }^{3}$, sendo as mulleres, en xeral, as máis prexudicadas xa que teñen que suprimir horas de lecer para poder facer fronte ás actividades que realizan, tanto retribuídas como non (Durán, 2000). O uso de indicadores de igualdade para analizar as diferenzas nos usos do tempo, permite avaliar a calidade de vida, autonomía, igualdade de oportunidades e grao de discriminación. Estas ferramentas estatísticas ofrecen unha visión máis completa das repercusións que implican os usos do tempo por xénero.

Nos seguintes apartados, exponse tras unha análise descritiva, os resultados dos índices por rexións e unha síntese dos resultados a través dunha análise multivariante. A información dispoñible da EET aparece desagregada por comunidades autónomas cunha marxe de erro recolleito na táboa nํㅡㄹ.2 situada no anexo.

\subsection{Análise descritiva}

A táboa ํo 2 presenta a media aritmética e os valores mínimos e máximos das variables (traballo retribuído $(\mathrm{R})$, coidados persoais $(\mathrm{P})$, educación $(\mathrm{E})$, traballo doméstico (D) e tempo libre (L)) que se utilizarán posteriormente no cálculo dos índices. Os indicadores descritivos desagréganse por xénero ( $\mathrm{H}$ : Home, M: Muller). Os resultados calculáronse a partir da duración media diaria adicada á actividade por comunidade autónoma, expresada en horas e minutos.

Táboa no 2. Medidas descritivas por xénero

\begin{tabular}{|r|c|c|c|c|c|c|c|c|c|c|}
\hline & $\mathbf{R}_{\mathbf{H}}$ & $\mathbf{R}_{\mathbf{M}}$ & $\mathbf{p}_{\mathbf{H}}$ & $\mathbf{P}_{\mathbf{M}}$ & $\mathbf{E}_{\mathbf{H}}$ & $\mathbf{E}_{\mathbf{M}}$ & $\mathbf{D}_{\mathbf{H}}$ & $\mathbf{D}_{\mathbf{M}}$ & $\mathbf{L}_{\mathbf{H}}$ & $\mathbf{L}_{\mathbf{M}}$ \\
\hline Media & $7: 70$ & $6: 40$ & $11: 36$ & $11: 30$ & $5: 00$ & $4: 73$ & $2: 31$ & $4: 28$ & $10: 30$ & $8: 53$ \\
\hline Mín & $7: 17$ & $6: 00$ & $11: 14$ & $11: 16$ & $4: 09$ & $4: 05$ & $2: 08$ & $3: 59$ & $8: 44$ & $7: 78$ \\
\hline Máx & $8: 32$ & $7: 04$ & $12: 07$ & $11: 52$ & $6: 06$ & $6: 21$ & $2: 55$ & $4: 56$ & $12: 27$ & $10: 20$ \\
\hline
\end{tabular}

Fonte: Elaboración propia a partir de datos da EET 2009-2010 (INE).

En España existe unha alta desigualdade por motivos de xénero no investimento do tempo. A participación en traballos retribuídos presenta elevadas diferenzas por xénero. A participación en actividades non retribuídas é moi desigual. Os homes españois adican moito menos tempo ás tarefas domésticas cas mulleres, como consecuencia dispoñen de máis tempo libre. As maiores diferenzas entre comunidades autónomas preséntanse nas actividades relacionadas co tempo libre, a educación e o traballo retribuído. Ao compararse os erros da mostraxe das diferentes Comunidades Autónomas coas diferenzas observadas,

3 García Sainz (1999) define a carga global do traballo como a suma do traballo retribuído e non retribuído. Na proposta realizada por esta investigadora o traballo retribuído refírese ao tempo investido nas ocupacións realizadas a cambio dunha retribución. O traballo non retribuído, pola contra, é a suma do tempo adicado ao traballo doméstico, aos coidados e o adicado ao traballo voluntario. 
obtéñense resultados estadisticamente significativos principalmente para as variables traballo retribuído, traballo doméstico e tempo libre.

A figura A1, incluída no Anexo, dispoñible na nota de prensa sobre a EET de 20092010, publicada polo INE no 2011, resalta estas diferenzas por rexións entre tempo libre e tempo comprometido (trabajo retribuído, estudos e tarefas domésticas). Madrid e Cataluña son as rexións nas que a súa poboación dispón de maior tempo comprometido, pero escaso tempo libre. En contraposición, en Canarias e A Rioxa o tempo comprometido é dos máis reducidos, en termos relativos, pero cunha alta disposición de actividades relacionadas co tempo libre.

5.2. Indicadores de igualdade. Os resultados dos diferentes índices de igualdade para as comunidades autónomas aparecen recollidos na táboa 3 e figura A2 (Anexo). Calculáronse a partir da media diaria adicada á actividade principal por comunidade autónoma ${ }^{4}$ expresada en horas e minutos. Os resultados detallados pódense consultar no anexo, na táboa nํㅡ‥3. Para a súa interpretación, considérese que se o indicador tomara o valor 100 significaría unha situación de igualdade entre home e muller. Dous dos índices -índice de discriminación de traballo doméstico e índice diferencial do traballo produtivo- sitúanse por enriba de 100 e, tres índices - índice diferencial de autonomía, índice de igualdade social e índice de discriminación de calidade de vida- toman valores por debaixo, sistematicamente en todas as comunidades autónomas. Os valores do índice de discriminación do traballo doméstico indican unha importante diferenza no tempo adicado ao traballo doméstico por xénero, como corroboran outros estudos (Durán, 2000; García Sainz, 2007; González e JuradoGuerrero, 2009).

Tabla 3. Indicadores de igualdad

\begin{tabular}{|l|c|c|c|c|c|}
\hline & $\begin{array}{c}\text { Índice da } \\
\text { discriminación } \\
\text { no traballo } \\
\text { doméstico }\end{array}$ & $\begin{array}{c}\text { Índice } \\
\text { de } \\
\text { igualdade } \\
\text { social }\end{array}$ & $\begin{array}{c}\text { Índice } \\
\text { discriminación } \\
\text { calidade de } \\
\text { vida }\end{array}$ & $\begin{array}{c}\text { Índice } \\
\text { diferencial } \\
\text { autonomía }\end{array}$ & $\begin{array}{l}\text { Índice } \\
\text { diferencial } \\
\text { traballo } \\
\text { productivo }\end{array}$ \\
\hline 1. Andalucía & 183,40 & 50,58 & 51,66 & 77,62 & 115,05 \\
\hline 2. Aragón & 188 & 45,98 & 46,76 & 74,26 & 119,14 \\
\hline 3. Asturias & 179,07 & 48,09 & 49,63 & 80,01 & 112,28 \\
\hline 4. Baleares & 160,98 & 57,91 & 57,46 & 90,37 & 119,94 \\
\hline 5. Canarias & 181,70 & 47,53 & 46,86 & 69,28 & 133,35 \\
\hline 6. Cantabria & 188,98 & 48,97 & 51,25 & 77,67 & 105,82 \\
\hline 7. Castilla-León & 194,61 & 45,03 & 45,81 & 76,39 & 121,10 \\
\hline 8. La Mancha & 206,33 & 42,09 & 43,75 & 71,10 & 114,46 \\
\hline 9. Cataluña & 182,40 & 50,97 & 52,38 & 88,06 & 112,47 \\
\hline 10. Valencia & 189,65 & 46,96 & 47,23 & 70,66 & 124,34 \\
\hline 11. Extremadura & 178,43 & 51,85 & 53,88 & 78,84 & 108,30 \\
\hline 12. Galicia & 179,58 & 49,30 & 50,64 & 78,92 & 113,73 \\
\hline 13. Madrid & 178,78 & 51,35 & 52,16 & 76,04 & 116,22 \\
\hline 14. Murcia & 200,13 & 43,49 & 44,97 & 68,26 & 114,72 \\
\hline 15. Navarra & 173,41 & 53,52 & 55,17 & 85,29 & 109,16 \\
\hline 16. País Vasco & 181,43 & 52,47 & 53,89 & 81,37 & 111,74 \\
\hline 17. La Rioja & 177,63 & 49,05 & 49,24 & 64,01 & 122,42 \\
\hline 18. Ceutay & 219,23 & 42,75 & 44,32 & 82,85 & 115,61 \\
\hline Melilla & & & & & \\
\hline
\end{tabular}

Fonte: Elaboración propia a partir da EET 2009-2010 (INE).

4 Dado que, a EET céntrase fundamentalmente nas actividades principais, estas foron as consideradas na análise. 
Nalgunhas comunidades autónomas, as mulleres chegan a adicar un 100\% ou máis de tempo ás tarefas domésticas con respecto ao investido polos homes. A cuantía desta diverxencia entre xéneros varía ostensiblemente entre comunidades. Así, no caso de Ceuta e Melilla, o valor deste índice chega a 219,23. As mulleres en Ceuta e Melilla adican a este tipo de actividades un 119,23\% máis de tempo co investido polos homes. As Illas Baleares $(160,98)$, é a comunidade autónoma, con menor discrepancia entre xéneros en canto ao traballo doméstico. As mujeres en Baleares adican a este tipo de actividades un 60,98\% máis de tempo cos homes.

Tamén obsérvanse diferenzas entre comunidades autónomas, nos niveis de desigualdade entre xénero en canto ao traballo produtivo e a autonomía.

O índice diferencial de traballo produtivo sitúase próximo a cen. Malia que aínda existen discrepancias entre o tempo adicado a traballos produtivos e non produtivos entre homes e mulleres, estas diferenzas non son moi elevadas, achegándose a unha situación próxima á igualdade por xénero en comunidades tales como Cantabria $(105,82)$, Estremadura $(108,3)$ e Navarra $(109,16)$. Cómpre considerar estes resultados con cautela, xa que unha situación de igualdade no índice diferencial de xénero pode reflectir unha distribución interna entre o traballo produtivo -necesidades persoais, educación ou tempo libre- moi diferente entre xéneros (Álvaro, 1996; Giménez-Nadal et al., 2012; Durán, 2012). Os maiores valores do índice diferencial de traballo produtivo corresponden ás Illas Canarias $(133,35)$, Valencia $(124,34)$ e A Rioxa $(122,42)$. Nas Illas Canarias, a desproporción entre traballos produtivos e non produtivos é un 33, 35\% maior nas mulleres que nos homes.

O índice diferencial de autonomía, con valores inferiores a cen, amosa, como en todas as comunidades autónomas, que o grao de autonomía das mulleres é moi inferior ao dos homes. A desigualdade por xénero en canto á autonomía presenta oscilacións destacables entre comunidades autónomas. O maior índice diferencial de autonomía corresponde ás Illas Baleares (90,37). As mulleres nas Illas Baleares teñen un 9,63\% menos de autonomía para repartir as actividades que queren realizar ao longo do día cós homes. En contraposición, A Rioxa ten un índice diferencial de autonomía de 64,01, o que indica que as mulleres na Rioxa teñen un 35,99\% menos de autonomía cós homes.

Os valores dos índices de igualdade social e discriminación de calidade son moi semellantes entre eles. Este feito observouse a nivel nacional noutras investigacións (Álvaro, 1996). Os valores inferiores a cen observados indican que a muller está peor situada nestes termos en todas as comunidades autónomas. A súa calidade de vida e igualdade social é un $50 \%$ inferior á dos homes, aproximadamente. Este nivel da calidade de vida e igualdade social é aproximadamente constante en todas as comunidades autónomas.

5.3. Análise multivariante. Co obxecto de efectuar comparacións e agrupacións entre CCAA, pode resultar útil estudar conxuntamente as 5 medidas de igualdade anteriores e sintetizar a información obtida. Este obxectivo pódese acadar mediante técnicas de análise multivariante. A análise multivariante é un conxunto de métodos estatísticos que teñen como finalidade analizar de forma simultánea conxuntos de datos multivariantes no senso de que hai varias variables medidas para cada obxecto ou individuo estudado. Neste traballo, proponse aplicar a análise factorial aos valores dos índices de igualdade por xénero para as diferentes comunidades autónomas suscitados anteriormente. O obxectivo da análise factorial é reducir a información contida nun número de variables orixinais a un conxunto máis pequeno de variables (factores) cunha perda mínima de información. A táboa $n^{0} 4$, recolle os resultados da medida de Kaiser-Meyer-Olkin (KMO) de adecuación da mostraxe e a proba de esfericidade de Barlett. As dúas probas valoran a adecuación dos datos dispoñibles sobre as medidas de igualdade a un modelo factorial. 
Táboa no 4. KMO e proba de Bartlett

\begin{tabular}{|cc|c|}
\hline Medida de Kaiser-Meyer-Olkin de adecuación da mostraxe: & 0,537 \\
Proba de esfericidade de Bartlett $\quad$ Chi-cadrado aproximado & 111,759 \\
Gl & 10 \\
Sig: & 0,000 \\
\hline
\end{tabular}

Fonte: Elaboración propia a partir da EET 2009-2010 (INE).

A medida KMO de adecuación da mostraxe obtén como resultado 0,537, por tanto, existe certa correlación entre os indicadores de igualdade. O nivel crítico asociado á proba de esfericidade de Bartlett indica que débese rexeitar a hipótese nula de incorrelación lineal entre as medidas de igualdade. Así pois, de acordo cos resultados deste contraste é adecuado aplicar a análise factorial.

Na táboa A4, no Anexo, denominada varianza total explicada, recóllense os autovalores da matriz de varianzas-covarianzas e a porcentaxe da varianza que representa cada un deles. Os autovalores expresan a cantidade da varianza total que está explicada por cada factor. A partir da información fornecida, retéñense dous factores ou compoñentes que conseguen explicar conxuntamente un $89,62 \%$ da variabilidade inicial. O primeiro compoñente explica o $65,96 \%$ da variabilidade dos datos e o segundo o $23,66 \%$. A variable peor explicada, nun $72,8 \%$ polos factores retidos, é o índice diferencial de autonomía. A variable mellor explicada, é o índice de igualdade social: o modelo factorial é capaz de explicar o 98,1\% da variabilidade orixinal da variable.

A táboa A6, amosa a solución factorial rotada. A matriz de compoñentes recolle as correlacións entre os compoñentes retidos e as variables iniciais. Entre os diferentes métodos de rotación optouse pola rotación ortogonal Varimax. O primeiro compoñente relaciónase directamente coa igualdade social e a calidade de vida e, inversamente, co traballo doméstico. O segundo factor, aparece fortemente relacionado coa autonomía, de forma directa, e inversamente, co traballo produtivo.

Táboa no 5. Clústers de comunidades autónomas

\begin{tabular}{|l|c|}
\hline \multicolumn{1}{|c|}{ Clústers } & Composición \\
\hline Clúster 1 & $\begin{array}{c}\text { Andalucía (1); Galicia (12); Asturias (3); Madrid (13); Estremadura (11); País Vasco } \\
\text { (16); Cataluña (9); Navarra (15); Cantabria (6) }\end{array}$ \\
\hline Clúster 2 & Baleares (4) \\
\hline Clúster 3 & Aragón (2); León (7); A Mancha (8); Murcia (14) \\
\hline Clúster 4 & Valencia (10); A Rioxa (17); Canarias (5) \\
\hline Clúster 5 & Ceuta e Melilla (18) \\
\hline
\end{tabular}

Fonte: Elaboración propia a partir da EET 2009-2010 (INE).

O segundo clúster comprende unha única Comunidade Autónoma, Baleares, na que aínda que as mulleres seguen amosando un saldo negativo fronte aos homes en canto á igualdade social, calidade de vida e traballo doméstico, esta discrepancia por xéneros é a menor observada entre todas as comunidades autónomas. No terceiro conglomerado, as discrepancias entre homes e mulleres en canto ao traballo doméstico e produtivo son moi elevadas. Isto quere dicir que as mulleres destas comunidades adican máis tempo a este tipo de traballos. Pola contra, son comunidades con baixos índices de igualdade social, discriminación con respecto á calidade de vida e diferencial de autonomía. Posto que estes índices toman valores inferiores a 100 en todas as comunidades autónomas, son estas 
comunidades comprendidas no clúster terceiro, as que menos fomentan a igualdade social, autonomía e calidade de vida das mulleres.No cuarto clúster, obsérvanse comunidades onde os niveis de autonomía das mulleres son moi baixos, pero a súa calidade de vida, igualdade social e tempo dedicado ao traballo doméstico presenta uns niveis moderados en comparación co resto de comunidades. O quinto clúster, representado por Ceuta e Melilla, destaca por presentar unha fenda por xénero en tempo adicado ás tarefas domésticas moi superior ao resto das comunidades autónomas e, uns niveis de calidade de vida e igualdade social moi baixos para as mulleres.

\section{Conclusións}

A finalidade principal da conciliación é acadar un equilibrio entre as esferas laboral, persoal e de lecer e, deste xeito, mellorar o benestar persoal, o clima laboral e a saúde das persoas. As estatísticas sobre os usos do tempo foron utilizadas, desde hai décadas, como aproximación ao estudo da conciliación da vida laboral e familiar (Joyce e Stewart, 1999). Neste traballo, empregouse a Enquisa de Emprego do Tempo (2009-2010), realizada polo INE, para analizar as desigualdades por xénero en usos do tempo observadas nas comunidades autónomas.Existen traballos previos nos que se analizan as estatísticas de usos do tempo a nivel nacional ou, específicamente, para unha comunidade (Álvaro, 1996; Durán, 1998; González e Xurado-Guerreiro, 2009; Legarreta, 2010; Rodríguez e Pis, 2010, Meil e Roguero, 2012). Á diferenza doutros estudos, o nivel de análise proposta é o conxunto de comunidades autónomas. Os últimos datos dispoñibles sobre usos do tempo nas comunidades autónomas empregáronse no cálculo dos índices de igualdade por xénero (Álvaro, 1994). O emprego desta ferramenta estatística permite desvelar as consecuencias que teñen estes usos en materias de igualdade social, calidade de vida, autonomía e traballo por xéneros.

Os valores dos índices permiten corroborar as fendas inherentes entre homes e mulleres e a persistencia de roles en España no tempo adicado ao traballo doméstico e ao traballo produtivo especialmente (Durán, 1991; Álvaro, 1996; Callejo et a 0., 2008, entre outros). Os niveis de igualdade social, autonomía e calidade de vida seguen a ser inferiores para o xénero feminino en todas as comunidades. Estes resultados apuntan á necesidade de promover medidas políticas e sociais que favorezan un aumento da calidade de vida, especialmente das mulleres. A análise complementaria con outras medidas, non só obxectivas senón tamén subxetivas ofrecería unha visión máis ampla dos factores determinantes nos niveis de calidade. "A medida e a análise da calidade de vida aseméllanse a un quebracabezas cun número elevado de pezas, de moi diversas formas e características, pero onde cada unha delas xoga un papel esencial, de forma que sen unha, o resultado final estaría incompleto" (Somarriba e Pena, 2009). Así mesmo, débense promover políticas que incrementen a igualdade entre sexos para, entre outras cousas, avanzar no reparto das tarefas do fogar e facilitar as transicións do mercado laboral. Malia os cambios sociais experimentados nos últimos anos, logo da xornada laboral son as mulleres as que adoitan adicarlle maior tempo ás tarefas do fogar. As diferenzas observadas entre comunidades autónomas no valor do índice de discriminación do traballo doméstico, apuntan a características económicas, culturais e/ ou sociais subxacentes aos territorios que inflúen decisivamente para que estas desigualdades oscilen.

A análise multivariante aplicada sobre os índices de igualdade obtidos, revela a existencia de cinco grupos de comunidades autónomas con diferenzas destacables entre elas en canto á conciliación familiar e laboral e, xa que logo, requerimentos diferentes para avanzar na conciliación da vida familiar e laboral. As comunidades autónomas de Andalucía, Galicia, Asturias, Madrid, Estremadura, País Vasco, Cataluña, Navarra e Cantabria (clúster 1), son aquelas nas que as diferenzas por xénero son menores. Pola contra, Aragón, León, Murcia e Castela-A Mancha (clúster 3) e Ceuta e Melilla (clúster 5) son as que menos promoven a 
igualdade social, autonomía e calidade de vida das mulleres. Por tanto, aínda que desenvolvéronse políticas e accións de xénero a nivel nacional e rexional dende finais dos anos 80, a persistencia da fenda por xénero mantense, especialmente nalgunhas comunidades autónomas que requiren campañas e intervencións específicas. Unha análise complementaria das características económicas e sociais destas comunidades en relación aos resultados obtidos, podería resultar relevante para determinar as accións máis efectivas. Unha maior desagregación, por comunidades autónomas, da estruturación do tempo diario en función do grupo social de pertenza, a idade, a relación co mercado laboral ou a posición na familia, permitiría fixar os colectivos sobre os que instituír as posibles medidas.

\section{Bibliografía}

- Álvaro, M. (1994): Propuesta de un sistema de Indicadores Sociales de Igualdad entre Géneros, Instituto de la Mujer y Ministerio de Trabajo e Inmigración, Madrid.

- Álvaro, P. (1996): Los Usos del tiempo como indicadores de la discriminación entre géneros, Instituto de la Mujer, Ministerio de Asuntos Sociales, Madrid.

- Arbaiza, M. (2000): "La «cuestión social» como «cuestión de género». Feminidad y trabajo en España (1860-1930)", Revista Historia Contemporánea, 21, pp. 395-458.

- Balbo, L. (1978): "La doble presencia”" en Borderías,C. Carrasco, C., Alemany, C. (Comp.). Las mujeres y los trabajos. rupturas conceptuales. Icaria, Barcelona, [1993], pp. 503-513.

- Borderías, C., Carrasco, C. , Almany, C. (comp.) (1994): Las mujeres y los trabajos. rupturas conceptuales, Icaria, Barcelona.

- Borrás, V., Torns, T., Morena, S. (2007): “Las políticas de conciliación. políticas laborales versus políticas de tiempo", Papers, 83, pp. 83-96.

- Callejo, J., Prieto, C., Ramos, R. (2008): “Cambios generales en el tiempo del trabajo profesional y de cuidados”, en Prieto, C., Ramos, R., Callejo, J. (coords.). Nuevos tiempos del trabajo. Entre la flexibilidad competitiva de las empresas y las relaciones de género, Centro de Investigaciones Sociológicas, Madrid, pp. $5-48$.

- Campillo, I. (2010): "Políticas de conciliación de la vida laboral y familiar en los regímenes de bienestar mediterráneos. los casos de Italia y España”, Política y Sociedad, 47,1, pp. 189-213.

- Carrasco, C. (2005): "Tiempo de trabajo, tiempo de vida: las desigualdades de género en el uso del tiempo", en CEPAL (ed.): El tiempo, los tiempos, una vara de desigualdad, Comisión Económica de las Naciones Unidas para América Latina y el Caribe (CEPAL), Santiago de Chiles pp. 51-79.

- Carrasco, C. (2006): "La economía feminista. una apuesta por otra economía", en Estudios sobre género y economía, M.Jesús Vara (coord). Editorial Akal, colección Economía Actual, 2006, pp. 29-53.

- Comisión Europea (2010): Europa 2020 Una estrategia para un crecimiento inteligente, sostenible e integrador, Documento COM (2010) 2020, Bruselas.

- De Luis, M.P., Martínez, A., Pérez, M. y Vela, M.J. (2002): “La flexibilidad de la empresa y la conciliación de la vida laboral y familiar", Boletín Económico de ICE, 2741, pp. 37-52.

- Durán, M.A. (1991): "El tiempo en la economía española", Información Comercial Española, 695, pp. 9-48.

- Durán, M.A. (1998): "La investigación sobre uso del tiempo en España en la década de los noventa. Algunas reflexiones metodológicas", Revista Internacional de Sociología (RIS), 18, pp. 163-189.

- Durán, M.A. (2000): “Concentración y reparto del trabajo no remunerado en los hogares", Cuadernos de Relaciones Laborales, 17, pp. 91-122.

- Durán, M.A. (2012): El trabajo no renumerado en la economía global, Fundación BBVA.

- Durán, M.A., Rogero, J. (2009): La investigación sobre el uso del tiempo, Cuadernos Metodológicos, 44, Centro de Investigaciones Sociológicas.

- Esping-Andersen, G. (2000): Fundamentos sociales de las economías postindustriales, Ariel, Barcelona.

- EUROFOUND, European Foundation for the Improvement of Living and Working Conditions (2010): Family Life and Work. Second European Quality of Life Survey, European Communities, Luxembourg.

- Fagan, C. (2007): Working conditions in the European Union: The gender perspective, EUROFOUND, Luxemburgo.

- García Sainz, C. (1999): La carga global de trabajo. Un análisis sociológico. Tesis doctoral inédita. Facultad de Ciencias Políticas y Sociología. Universidad Complutense de Madrid.

- García Sainz, C. (2005): "Aspectos conceptuales y metodológicos de las encuestas de uso del tiempo en España" en Aguirre, R., García Sainz, C. y Carrasco, C. (EDS). El tiempo, los tiempos, una vara de desigualdad, Santiago de Chile. Unidad Mujer y Desarrollo, CEPAL, Naciones Unidas. pp 35-50.

- García Sainz, C. (2007): "Trabajos y tiempos. La consideración del trabajo y los usos diferenciales de los tiempos" en Incorporamos el lila al currículo educativo. Las mujeres también cuentan. VV.AA. pp 23-37. Enseñanza, Secretaría de la Mujer de CCOO, Madrid. 
- Gershuny,J. (1987): “Estilo de vida, estructura económica y uso del tiempo”, REIS, 38, pp.163-161.

- Gershuny, J. (2000): Changing Times. Work and Leisure in Postindustrial Society, Oxford, Oxford University Press.

- Giménez-Nadal, J., Molina, J., Ortega-Lapiedra, R. (2012): “Self-employed mothers and the work-family conflict", Applied Economics, 44, 17, pp. 2133-2147.

- González, M., Jurado-Guerrero, T. (2009): “¿Cuándo se implican los hombres en las tareas domésticas? Un análisis de la Encuesta de Empleo del Tiempo", Panorama Social, 10, pp. 65-81.

- Hochschild, A. R. (1989): The second shift: Working Parents ant the Revolution at Home, Viking, NY.

- Hook, J. (2010): "Gender Inequality in the Welfare State. Sex Segregation in Housework, 1965-2003", American Journal of Sociology, 115, pp. 1480-1523.

- INE (2011): Encuesta del empleo del tiempo 2009-2010. Metodología, INE.

- Joyce, M. Stewart, J. (1999): “What Can We Learn from Time-Use Data?”, Monthly Labor Review, 122, 8, pp. 3-6.

- Kovács, I., Casaca, S. F. (2007): "Flexibilidad y desigualdad en el trabajo. tendencias y alternativas europeas", Sociología del Trabajo, 61, pp. 99-124.

- Legarreta, M. (2008): "El tiempo donado en el ámbito doméstico. Reflexiones para el análisis del trabajo doméstico y los cuidados", Cuadernos de Relaciones Laborales, 26, 2, pp. 45-69.

- Legarreta, M. (2010): Tiempo y Desigualdades de Género. Distribución social y políticas del tiempo, Instituto Andaluz de la Mujer, Junta de Andalucía.

- Lombardo, E., Bustelo, M. (2012): "Political Approaches to Inequalities in Southern Europe. A Comparative Analysis of Italy, Portugal, and Spain", Social Politics, 19, 4, pp. 572-595.

- López, P., Lozares, C. (2007): "La conciliación entre las exigencias del ámbito productivo y las condiciones sociofamiliares. Estudio de caso de una empresa", Papers, 83, pp. 123-144,

- Marcenaro, O. (2008): “Una aproximación cuantitativa a los costes de conciliación en los hogares andaluces". Documento de Trabajo E2008/ 02, Fundación Centro de Estudios Andaluces.

- Marcenaro, O., West, L. (2009): "Una cuantificación de las asimetrías por género en materia de conciliación”, Investigaciones Regionales, 14, pp. 107-130.

- Meil,G.,Rogero, J.(2012): "Las Encuestas de Empleo del Tiempo como instrumento para analizar el re-parto del trabajo remunerado y no remunerado", Índice. Revista de estadística y sociedad, 51,p.20-22.

- Meil, G.; García, C.; Luque, M. Á. y Ayuso, L. (2010): El desafío de la conciliación de la vida privada y laboral en las grandes empresas, Universidad Autónoma de Madrid, Madrid.

- Moreno, S., Borràs, V. (2013): El temps de treball remunerat i no remunerat a partir de l'EUT2010-2011. La mesura de les desigualtats amb la cárrega total de treball, IDESCAT, Barcelona.

- OCDE (2007): Babies and Bosses Reconciling Work and Family Life: A Synthesis of Findings for OECD Countries, OCDE, Paris.

- Papí, N. (2005): "La conciliación de la vida laboral y familiar como proyecto de calidad de vida desde la igualdad", RES. Revista Española de Sociología, 5, pp.91-107.

- Pazos, M. (2007): Economía e Igualdad de Género. Retos de la. Hacienda Pública en el siglo XXI. Instituto de Estudios Fiscales, Madrid.

- Pearson, R., Sweetman, C. (2011): Gender and the economic crisis, Oxfam GB. Practical Action Publishing, Oxford.

- Pedrero, M. (2004): "Sabia virtud de conocer el tiempo el uso del tiempo en función del género: análisis comparativo entre México y Europa", Revista de Economía Mundial, 10/11, pp.77-101.

- Poelmans, S. (2001): "Individual and organizational issues in work- family conflict", Research Paper, 444, IESE, Universiy of Navarra, Barcelona.

- Ramos, M.D. (1998): La medida del mundo. género y usos del tiempo en Andalucía, Instituto Andaluz de la Mujer, Sevilla.

- Rodríguez, M.X, Pis,E. (2010): "Midiendo con perspectiva de género. Reflexiones a partir de la en-cuesta de los usos del tiempo de los hogares de Galicia”, Revista Galega de Economía,19-2, p.1-24.

- Scott, J. W. (1993): "La mujer trabajadora en el siglo XIX”, en Duby, G., Perrot, M. (dir.): Historia de las mujeres. Tomo IV, Taurus, Madrid.

- Somarriba, N., Pena, B. (2009): “La medición de la Calidad de Vida en Europa, el papel de la información subjetiva", Revista de Estudios de Economía Aplicada, 27, 2, pp. 373-397.

- Tobio, C. (2005): Madres que trabajan. Dilemas y estrategias, Cátedra, Madrid.

- Torns, T., Borrás, V., Moreno, S., Recio, C. (2008): “Las políticas de tiempo en Europa”, Revista Papers, 49, pp. 77-84.

- Zedeck, S., Mosier, K. (1990): "El trabajo en la familia y la organización que lo emplea", American Psychologist, 45, pp. 240-251.

Anexo on line: http:/ / www.usc.es/ revistas/ index.php/ rge, and http:// https:// ideas.repec.org/ s/ sdo/ regaec.html 


\section{Anexo .}

Táboa A1

\begin{tabular}{|l|c|}
\hline Comunidades autónomas & Vivendas \\
\hline Andalucía & 1.272 \\
Aragón & 494 \\
Asturias & 440 \\
Baleares & 452 \\
Canarias & 544 \\
Cantabria & 370 \\
Castilla-León & 650 \\
Castilla La Mancha & 516 \\
Cataluña & 1.274 \\
Valencia & 894 \\
Extremadura & 414 \\
Galicia & 684 \\
Madrid & 1.126 \\
Murcia & 456 \\
Navarra & 736 \\
País Vasco & 538 \\
La Rioja & 358 \\
Ceuta y Melilla & 320 \\
\hline Total & 11.538 \\
\hline
\end{tabular}

Fuente: INE (2011).

Táboa A2.

\begin{tabular}{|l|c|c|c|c|c|c|c|c|c|c|}
\hline CCAA & $\mathbf{( 1 )}$ & $\mathbf{( 2 )}$ & $\mathbf{( 3 )}$ & $\mathbf{( 4 )}$ & $\mathbf{( 5 )}$ & $\mathbf{( 6 )}$ & $\mathbf{( 7 )}$ & $\mathbf{( 8 )}$ & $\mathbf{( 9 )}$ & $\mathbf{( 1 0 )}$ \\
\hline Andalucía & 0,78 & 2,18 & 5,23 & 1,94 & 9,18 & 2,12 & 2,68 & 4,83 & 2,3 & 1,11 \\
\hline Aragón & 0,8 & 3,96 & 9,07 & 2,34 & 10,86 & 5,84 & 5,89 & 5,51 & 3,47 & 5,91 \\
\hline Asturias & 0,86 & 3,47 & 15,38 & 4,17 & 11,85 & 8,59 & 4,87 & 5,68 & 2,31 & 3,92 \\
\hline Baleares & 1,38 & 3,44 & 14,94 & 3,1 & 14,37 & 9,36 & 3,89 & 8,11 & 6,38 & 3,72 \\
\hline Canarias & 0,99 & 3,74 & 10,83 & 3,12 & 5,92 & 5,09 & 7,9 & 8,39 & 3,76 & 5,04 \\
\hline Cantabria & 0,72 & 2,68 & 9,06 & 1,75 & 13,24 & 4,54 & 6,46 & 8,71 & 6,5 & 5,53 \\
\hline Castilla-León & 1,02 & 3,76 & 11,52 & 3,68 & 15,41 & 5,3 & 3,76 & 3,79 & 2,78 & 5,67 \\
\hline La Mancha & 0,98 & 3,46 & 5,89 & 2,99 & 9,86 & 5,08 & 5,85 & 3,69 & 3,74 & 3,18 \\
\hline Cataluña & 0,54 & 1,58 & 7,31 & 2,51 & 6,95 & 3,18 & 3,83 & 5,75 & 2,7 & 2,3 \\
\hline Valencia & 0,91 & 2,48 & 5,32 & 3,77 & 10,46 & 4,64 & 4,45 & 3,66 & 3,02 & 3,1 \\
\hline Extremadura & 0,88 & 3,16 & 14,4 & 5,04 & 8,02 & 4 & 5,77 & 5,13 & 4,48 & 10,76 \\
\hline Galicia & 0,75 & 1,67 & 5,45 & 2,23 & 8,39 & 3,76 & 2,92 & 5,54 & 3,66 & 3,16 \\
\hline Madrid & 0,77 & 1,92 & 5,9 & 2,2 & 8,91 & 3,9 & 3,43 & 4,35 & 2,54 & 1,9 \\
\hline Murcia & 1,12 & 3,49 & 7,71 & 5,03 & 22,63 & 5,31 & 11,3 & 7,32 & 2,52 & 3,32 \\
\hline Navarra & 0,91 & 2,87 & 10,27 & 4 & 11,21 & 7,72 & 2,3 & 5,15 & 2,78 & 5,98 \\
\hline País Vasco & 1,08 & 3,36 & 15,99 & 3,03 & 12,48 & 6,41 & 4,69 & 13,04 & 5,11 & 7,6 \\
\hline La Rioja & 0,63 & 3,13 & 12,85 & 3,4 & 12,38 & 8,36 & 6,63 & 8,79 & 3,82 & 6,41 \\
\hline Ceuta y Melilla & 1,47 & 3,56 & 8,18 & 6,44 & 17,59 & 3,1 & 5,91 & 5 & 4,93 & 5,52 \\
\hline
\end{tabular}

Fonte: EET 2009-2010 (INE). (1) Coidados persoais (2) O traballo remunerado, (3) Estudos (4) Casa e

Familia (5), o traballo voluntario e reunións, (6) A vida social e entretemento (7) actividades ao aire libre e deportes, (8) Hobbies e no ordenador (9) Medios (10) Viaxes e uso do tempo non especificado. 
Tabla A3. Índices de igualdad

\begin{tabular}{|c|c|}
\hline Indicador & Expresión de cálculo \\
\hline Índice de Igualdad Social & $11 S=\frac{\frac{\mathbf{R}_{M}+E_{M}+P_{M}+L_{M}}{D_{M}}}{\frac{R_{H}+E_{H}+P_{H}+L_{H}}{D_{H}}}$ \\
\hline $\begin{array}{c}\text { Índice de Discriminación respecto a la } \\
\text { Calidad de Vida }\end{array}$ & $\mathrm{IDC}=\frac{\frac{\mathrm{E}_{\mathrm{M}}+\mathrm{P}_{\mathrm{M}}+\mathrm{L}_{\mathrm{M}}}{\mathrm{D}_{M}}}{\frac{\mathrm{E}_{\mathrm{H}}+\mathrm{P}_{H}+\mathrm{L}_{H}}{\mathrm{D}_{H}}}$ \\
\hline Îndice Diferencial de Autonomía & $\mathrm{IDA}=\frac{2 \mathrm{~L}_{\mathrm{M}}+\mathrm{E}_{\mathrm{M}}+\mathrm{R}_{\mathrm{M}}-\frac{1}{2 \mathrm{D}_{M}}-\mathrm{P}_{\mathrm{M}}}{2 \mathrm{I}_{\mathrm{H}}+\mathrm{E}_{\mathrm{H}}+\mathrm{R}_{\mathrm{H}}-\frac{1}{2 \mathrm{D}_{\mathrm{H}}}-\mathrm{P}_{\mathrm{H}}}$ \\
\hline $\begin{array}{c}\text { Índice de Discriminación Respecto al } \\
\text { Trabajo Doméstico }\end{array}$ & $\mathrm{IDD}=\frac{\mathbf{D}_{\mathrm{M}}}{\mathbf{D}_{\mathrm{H}}}$ \\
\hline $\begin{array}{c}\text { Índice Diferencial Respecto al Trabajo } \\
\text { Productivo }\end{array}$ & $\mathrm{IDP}=\frac{\frac{\mathbf{R}_{M}+\mathrm{D}_{M}}{E_{M}+\mathrm{P}_{M}+\mathrm{L}_{M}}}{\frac{\mathbf{R}_{H}+D_{H}}{E_{H}+P_{H}+L_{H}}}$ \\
\hline
\end{tabular}

Fonte: Álvaro (1994).

Figura A1. Tempo comprometido e lecer nun día medio. CCAA

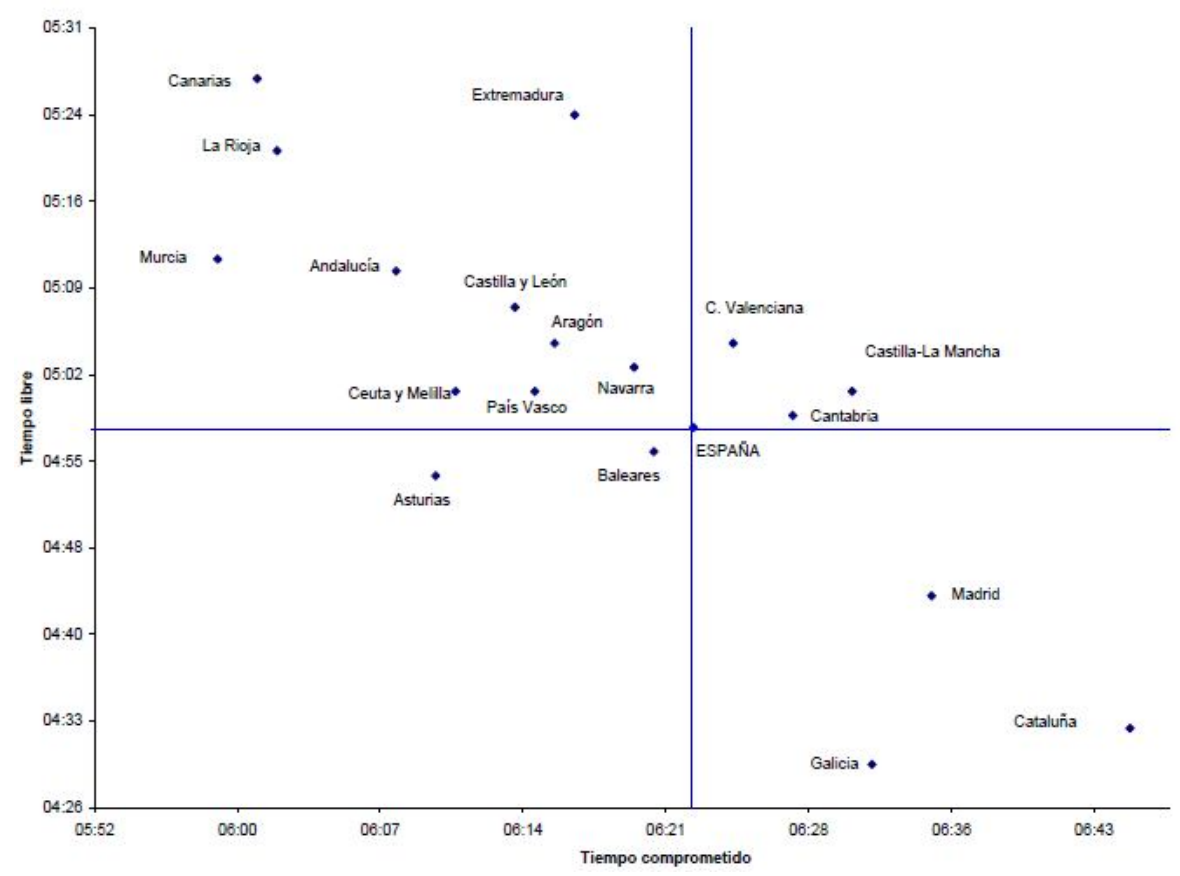

Fuente: INE (2011). 
Figura A2. Indicadores de igualdade por Comunidades Autónomas

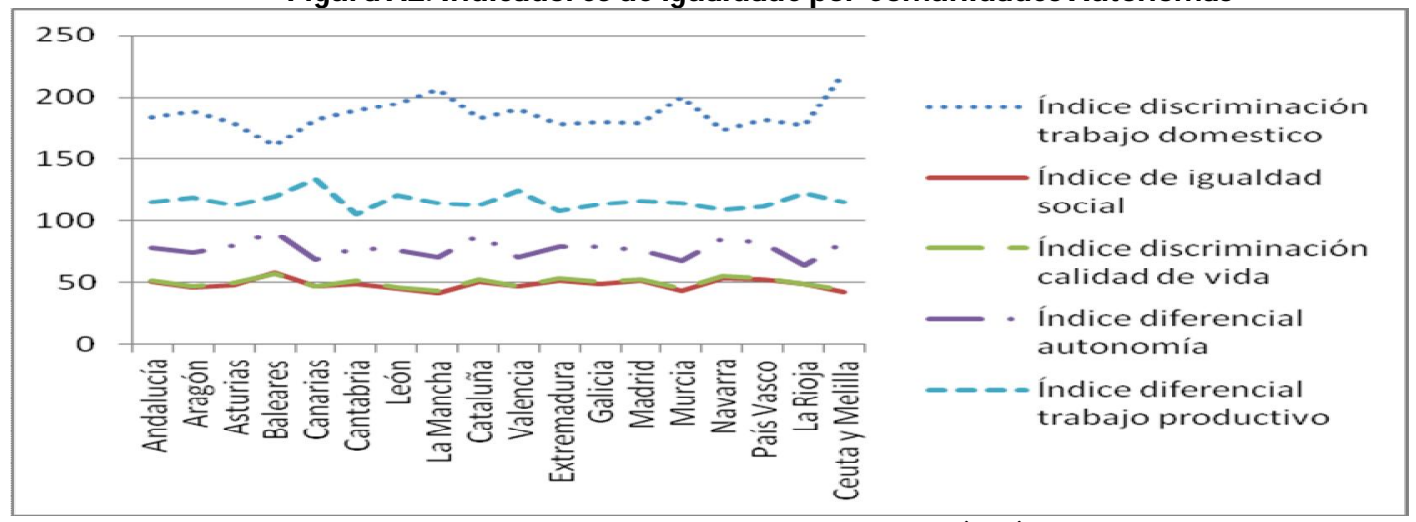

Fonte: Elaboración propia a partir de la EET 2009-2010 (INE).

Figura A3. Posición das Comunidades Autónomas, en termos de indicadores de igualdade de xénero

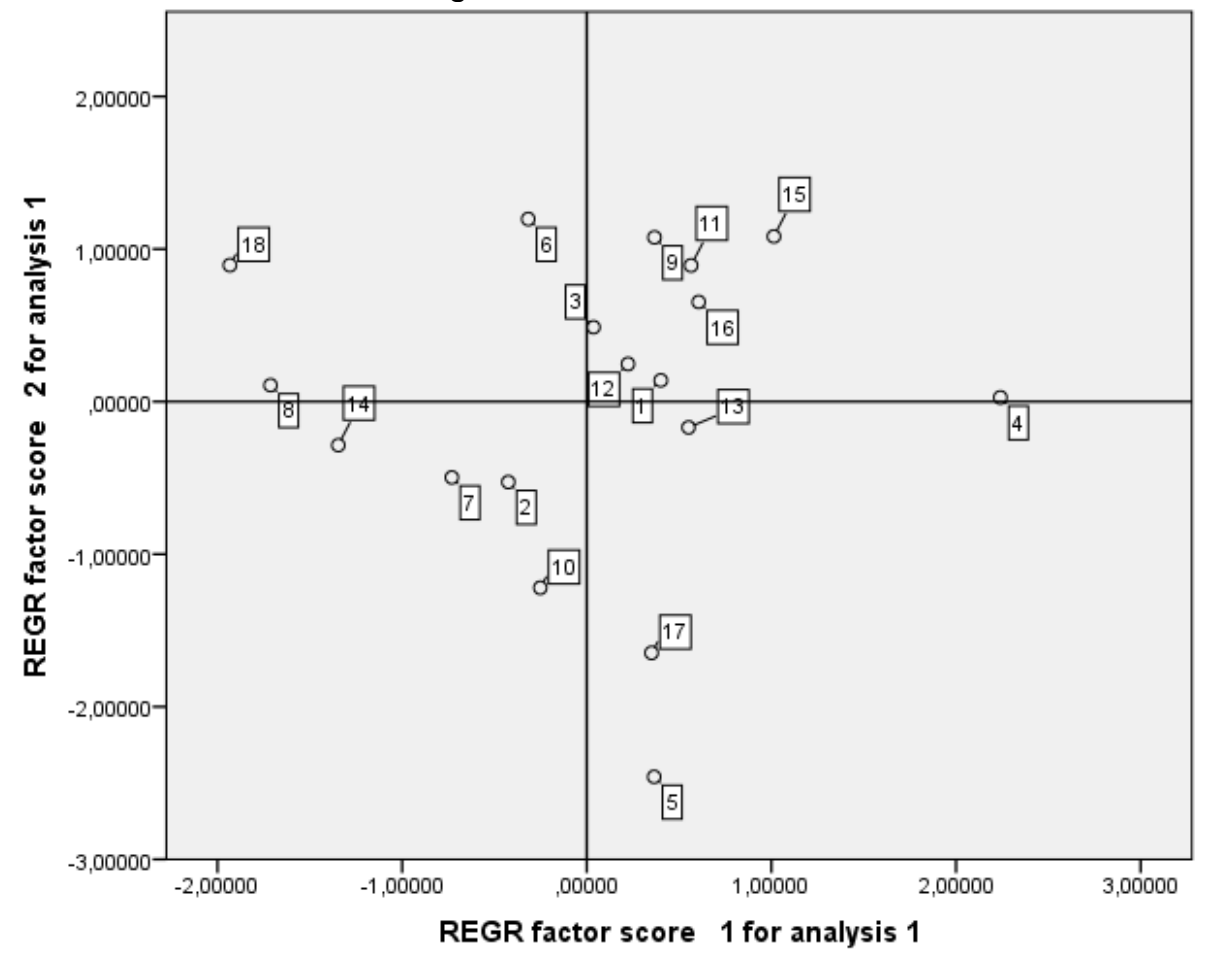

Fuente: Elaboración propia a partir de la EET 2009-2010 (INE). 
Tabla A4. Varianza total explicada

Fonte: Elaboración propia a partir de la EET 2009-2010 (INE).

\begin{tabular}{|c|c|c|c|c|c|c|}
\hline \multirow[t]{2}{*}{ Componente } & \multicolumn{3}{|c|}{ Autovalores iniciales } & \multicolumn{3}{|c|}{$\begin{array}{l}\text { Sumas de las saturaciones al } \\
\text { cuadrado de la extracción }\end{array}$} \\
\hline & Total & $\begin{array}{l}\% \text { de la } \\
\text { varianza }\end{array}$ & $\begin{array}{c}\% \\
\text { acumulad } \\
0\end{array}$ & Total & $\begin{array}{c}\% \text { de la } \\
\text { varianza }\end{array}$ & $\begin{array}{c}\% \\
\text { acumulad } \\
0\end{array}$ \\
\hline 1 & 3,298 & 65,961 & 65,961 & $\overline{3,298}$ & 65,961 & 65,961 \\
\hline 2 & 1,183 & 23,668 & 89,629 & 1,183 & 23,668 & 89,629 \\
\hline 3 & 0,453 & 9,052 & 98,681 & & & \\
\hline 4 & 0,062 & 1,237 & 99,918 & & & \\
\hline 5 & 0,004 & ,082 & 100,000 & & & \\
\hline
\end{tabular}

Método de extracción: Análise de Compoñentes Principais.

Tabla A5. Comunalidades

\begin{tabular}{|l|c|}
\hline \multicolumn{1}{|c|}{ Índices } & Comunalidades \\
\hline Índice de discriminación respecto al trabajo doméstico & 0,938 \\
\hline Índice de igualdad social & 0,981 \\
\hline Índice de discriminación respecto a la calidad de vida & 0,980 \\
\hline Índice diferencial de autonomía & 0,728 \\
\hline İndice diferencial respecto al trabajo productivo & 0,854 \\
\hline
\end{tabular}

Método de extracción: Análisis de Componentes principales.

Fuente: Elaboración propia a partir de la EEY 2009-2010 (INE).

Tabla A6. Matriz de compoñentes rotados

\begin{tabular}{|l|c|c|}
\hline \multirow{2}{*}{} & \multicolumn{2}{|c|}{ Componente } \\
\cline { 2 - 3 } & $\mathbf{1}$ & $\mathbf{2}$ \\
\hline Índice da discriminación en materia de traballo doméstico & $-0,968$ & 0,046 \\
\hline Índice de igualdade social & 0,964 & 0,229 \\
\hline Índice de discriminación en relación á calidade de vida & 0,903 & 0,406 \\
\hline Índice diferencial respecto ao traballo produtivo & 0,016 & $-0,924$ \\
\hline Índice diferencial de autonomía & 0,438 & 0,732 \\
\hline
\end{tabular}

Método de extracción: Análise de Compoñentes Principais. Rotación Método: Varimax con normalización Kaiser. Fonte: EET from 2009-2010 (INE) para o Desenvolvemento. 